\title{
A Review on Porous EDM Electrodes
}

\section{Hitesh Sharma*}

Faculty of Technology and Sciences, Department of Physical Sciences, Lovely Professional University, Phagwara, Punjab, India

\begin{abstract}
In the past years many researchers have done various advancements in material removal rate, wear of electrode is improved and various researches had done on physical and electrical parameters of EDM machine. This new research contributes the similar objectives to enhance the material removal rate and to increase the life of electrode by reducing the wear rate of electrode. So this paper review the past research work done on porous electrodes to improve the life of electrode and to reduce the lift up time of electrode to flush debris and various work on porous electrodes to reduce lift up time.
\end{abstract}

\section{Introduction}

Electrical discharge machining is the advances machining process in which there is no direct contact between the work pieces invented by two different scientists belongs from Russia, Dr. B.R. Lazarenko and Dr. N.I. Lazarenko in 1943. The spark generator was first used in 1943, known as Lazarenko circuit. And it was used for many years in power supply for EDM also been used in many current applications. Lazarenko circuit used resistance capacitance type of electric supply source. And was broadly used in 1950's also played an important role later in successive improved development in EDM. Other development in 1960's was pulse and solid state generator reduced past problems with weak electrodes as well as inventions of orbiting system. And while 1970, a number of electrodes were introduced to create cavity. And further in 1980s the computer numerical controlled (CNC) was introduced in USA.

\section{Components of EDM}

Work piece: All the material which conducts electricity can be the work piece material for EDM.

Dielectric fluid: EDM setup consists of dielectric fluid in which the electrode and the work piece material is submerged.

Servo system: It feed the electrode by sending the voltage in terms of pulse by command of servo system.

Electrode: It is the tool of EDM which determine the shape of work piece cavity to be made.

Power supply: The power supply is the main part of EDM system, which converts the AC in to DC in means of pulse to gain the discharge at machining zone.

DC pulse generator: It supplies the DC current in the pulse form, with the suitable currant and voltage value for specific amount of the time.

\section{Principle of EDM}

The principle of EDM is to use the electric spark to erode the work piece by setting some amount of voltage and current value as how much amount of spark we need to erode material. These sparks are produced in dielectric fluid in between the work piece and electrode. And this spark can be considered as the actual cutting tool. As much the intensity of current as much it penetrates the work piece material. And yet there is no mechanical contact between work piece and electrode. During the spark formation the work piece material melts or vaporizes due to the much amount of heat. The volume of material removed by the single spark is small. It is basically in the range of $106-104 \mathrm{~mm}^{3}$, but this basic process repeats at least 10,000 times in a second. The first voltage which is generally given is of $200 \mathrm{~V}$. and the breakdown of the dielectric is achieved when the electrode moves towards the material of work piece. And it increases the electric field in the zone of gape and in increases until reaches the value until the breakdown takes place. The location of breakdown is basically the closet point of the electrode and work piece material. And it also depends how much dielectric particles present as the location when the breakdown occur the voltage value gets down and the current increase abruptly. And now the presence of current is possible in the dielectric. Because the dielectric has been ionized at this state and plasma is generated over in the gap between electrode and work-piece. A discharge current then formed and continuous bombardment takes place which is of ions and electrons. And hence the great heating of metal takes place, and the molten metal pool form at the location, from which some amount of metal vaporize at the starting. And the molten metal pool increase in size with time. The gap between the work piece and electrode is also a very important parameter. Typically it is to be around 10-100 micro-meter (increasing gap with increasing discharge current should be there else the penetration will be very high). At the end of discharge the current and voltage should be shut down. The plasma implodes in and under the pressure of dielectrics. Hence the metal pool is sucked up into the dielectric which leaves the small crater on the surface of work piece of material (Figures 1 and 2).

\section{Major parameters of EDM}

These parameters generally categories in two major parts:

- Process parameters

- Performance parameters.

Process parameters: These are used to handle the performance machining. And are generally the changeable and controllable inputs

${ }^{*}$ Corresponding author: Sharma H, Faculty of Technology and Sciences, Department of Physical Sciences, Lovely Professional University, Phagwara, Punjab, India, Tel: +91 1800102 4431; E-mail: hiteshsharma1995@hotmail.com

Received March 27, 2018; Accepted April 22, 2018; Published April 27, 2018

Citation: Sharma H (2018) A Review on Porous EDM Electrodes. J Appl Mech Eng 7: 304. doi:10.4172/2168-9873.1000304

Copyright: (c) 2018 Sharma H. This is an open-access article distributed under the terms of the Creative Commons Attribution License, which permits unrestricted use, distribution, and reproduction in any medium, provided the original author and source are credited. 


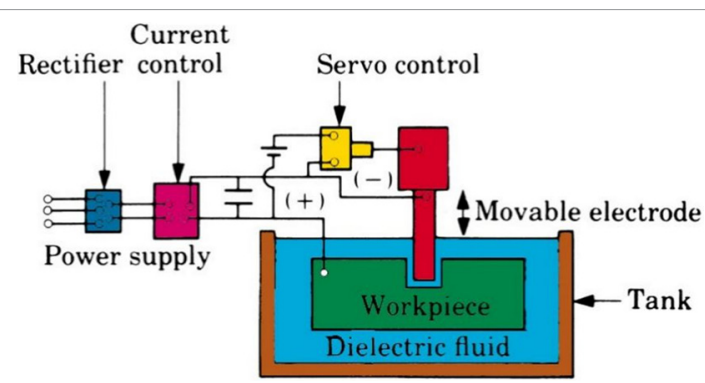

Figure 1: EDM process.

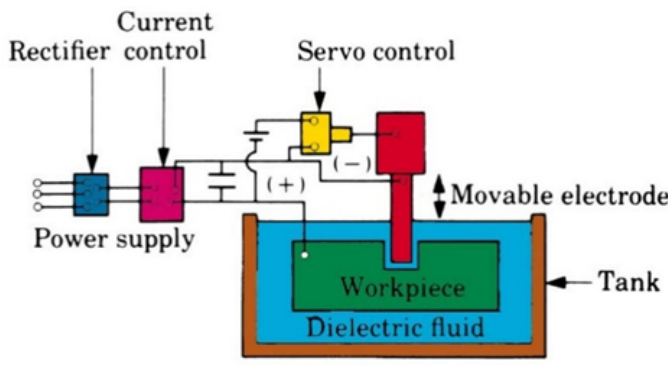

Figure 2: Die sinking EDM.

\begin{tabular}{c|c|c|}
$\begin{array}{c}\text { Measures } \\
\begin{array}{c}\text { Material } \\
\text { removal rate } \\
\text { (MRR) }\end{array}\end{array}$ & $\begin{array}{c}\text { It is the performance measure for the erosion rate, or we can say } \\
\text { it tell the speed of machining of the work-piece. It expressed in } \\
\text { terms of volumetric amount of the work-piece. }\end{array}$ \\
$\begin{array}{c}\text { Tool wear } \\
\text { rate (TWR) }\end{array}$ & $\begin{array}{c}\text { It is the performance measure which tells the erosion rate of the tool, } \\
\text { or we can say at what amount of speed the tool is degrading. It is } \\
\text { expressed in terms of volumetric amount of the tool. }\end{array}$ \\
$\begin{array}{c}\text { Tool ratio } \\
\text { (TR) }\end{array}$ & $\begin{array}{c}\text { It is the ratio of TWR/MRR. It is used to measure the optimum } \\
\text { combination of material to compensate the TWR and MRR. }\end{array}$ \\
$\begin{array}{c}\text { Surface } \\
\text { quality (SQ) }\end{array}$ & $\begin{array}{c}\text { It is a huge performance measure, helps in finding the HAZ, } \\
\text { surface finish and how is the quality of machined surface. And } \\
\text { also include the detail of density of recast layer. }\end{array}$ \\
$\begin{array}{c}\text { Surface } \\
\text { roughness } \\
\text { (SR) }\end{array}$ & $\begin{array}{c}\text { It is the surface parameter, measures the amplitude variation } \\
\text { of the surface. Which translate to roughness? It include detail } \\
\text { of Ra(mean roughness), } \mathrm{R}_{\text {max }} \text { and Rq (mean square surface } \\
\text { roughness) }\end{array}$ \\
$\begin{array}{c}\text { Heat affected } \\
\text { zone (HZ) }\end{array}$ & $\begin{array}{c}\text { It is the volume of work-piece which didn't melt during the } \\
\text { discharge, but affected and transformed the phase as similar to } \\
\text { the heat treatment. }\end{array}$ \\
\hline $\begin{array}{c}\text { Recast layer } \\
\text { thickness }\end{array}$ & $\begin{array}{c}\text { It is the layer which solidifies again after melting, due to not } \\
\text { proper flushing or because of the cold slow flushing. }\end{array}$ \\
\hline
\end{tabular}

Table 1: Performance parameters.

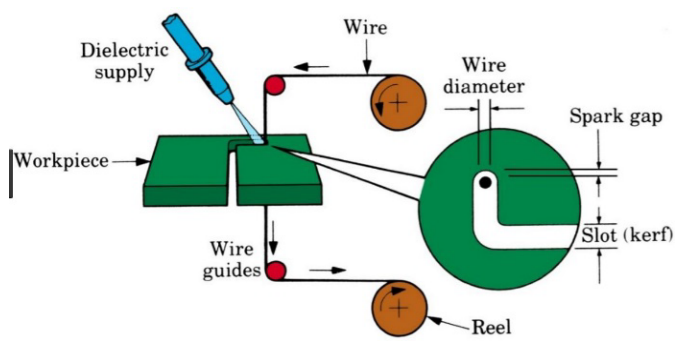

Figure 3: Wire EDM.

to the machine. And measures the condition in which the machining process is carried out. And these will affect the result of machining and are used by gauging many performance measures.

\section{A. Electrical parameters}

- Polarity

- Discharge voltage

- Gap voltage

- Peak current

- Average current

- Pulse ON time

- Pulse OFF time

- Pulse frequency

- Pulse wave form

- Electrode gap

- Duty factor

\section{B. Non-electrical parameters}

- Electrode lift time

- Working time

- Nozzle flushing

- Gain

- Type of dielectric

\section{Powder based parameters}

- Powder type

- Powder concentration

- Powder conductivity

- Powder size

- Powder density

\section{Powder based parameters}

- Electrode shape

- Electrode size

- Electrode material

Performance parameters: These help in identifying and measure the results of various processes (Table 1).

\section{Types of EDM}

Generally there are two types of EDM

Die Sinking EDM: It is the cavity type or volume EDM. This in used to make cavity or making the dies. In this workpiece and electrode are submerged in dielectric fluid. The work and electrode are connected to suitable power supplies. The power supplies create the voltage potential. As the electrode move towards the work, the dielectric breaks. And form a plasma channel. And the spark jumps. These spark strike one at a time usually because it is very difficult that the inner electrode have same electrical properties at all the point if plane. And thus the spark changes the location. These sparks happens in huge amount in all the location and metal melts. And when the work erodes the electrode automatically goes down by machine itself so that the process continues.

Wire EDM: Wire EDM also known as the spark EDM. It is the electro thermal production process. In this process single metal strand 
wire is used to machine the work in conjunction with de-ionized water (used to conduct electricity) allows the wire to cut metal by the use of electrical sparks and heat. And also the work-piece is submerged in tank of dielectric. It can cut plates as thick as $300 \mathrm{~mm}$ and to make the punching tools, the die of hard metal can also be form which are hard to machine. The benefit is the low residual stress forms. Very less mechanical properties of the work changes (Figure 3).

\section{Advantages of EDM}

- +/- 0.005 tolerances limit can be achieved.

- Material hardness does not affect process.

- Complex shapes cutting and thin walled geometry can produce without distortion.

- EDM process has no-contact and no-force that make it well suited for delicate or fragile parts that cannot take the stress of traditional machining (Figure 1).

- The EDM process produces no burrs.

\section{Disadvantages of EDM}

- Can only machine materials which are conductive.

- Much expensive process than conventional milling or turning methods.

- Slow production rate.

\section{Application Areas of EDM}

- To make hardened steel dies, wire drawing and extrusion dies, header dies, stamping tools, header die, forging die and intricate mould cavities.

- Best for making fragile parts which are very sensitive to mechanical forces.

- Micro pins, cavities and micro nozzle can be easily produced.

\section{Literature Review}

Shibayama and Kunieda et al. [1] Researched on EDM electrode made with the help of electrolyte jet machining, they created multichannel on copper electrode having width of $10 \mathrm{~mm}$ and thickness $2 \mathrm{~mm}$. they made it in two half and then bonded these two half with the help of diffusion bonding at a temperature of $1073 \mathrm{~K}$, bonding force $9 \mathrm{MPa}$ and loading time was 120 minutes. They compared two experiments one with dripping with medium flow and jump flushing. Material removal rate for drip flushing was two times higher than the flow flushing. Also there were no problems faced in creating deep groves in both the methods. And the same geometry of tool was replicated because the holes were in size of $0.12 \mathrm{~mm}$.

Guu et al. [2] researched on workpiece rotation effect on EDM. They found it effective to use, results indicated that debris Particles in the gap inevitably increased the discharge instability in conventional EDM. Also the centrifugal forces help in gap flushing. Surface roughness decrease with increasing speed. MRR was found twice if the previous method. Thewsey et al. researched on thermal conductivity of porous copper sintered by lost carbonate process. And they got that electrical conductivity increases with the relative density. Also thermal conductivity increases with the relative density was observed. Both the values were a bit different because impurities and oxides contribute to thermal conductivity but not to the electrical conductivity. Zhao et al. [3] researched on selective laser sintered electrode and they found that it can be used as EDM electrode if they use it for rough or medium finishing operations. The surface roughness of the cavity the electrode made was acceptable. Santanu Dey et al. researched on graphite and copper electrode and they found that for lower values of parameters generally for finishing the graphite electrode is superior, but for the maximum MRR the copper electrode is best on higher value parameters where finish requirements are not significantly desired researched and found that for the copper foam the thermal conductivity is enhanced by $60-70 \%$ and they examined that the resistance is directly proportional to the density. Balasubramanian Researched on cast and sintered electrode performance on $\mathrm{EN}-8$, he found that the MRR is more for sintered copper electrode, and tool wear wear rate is also high but the wear ratio was less. And he found that the surface roughness was less for cast electrode. But the results were opposite for the work piece Die steel. The reason was the electrical parameters was different for machining different work pieces.

Amorim et al. [4] made EDM porous electrode of Mo-CuNi powder with the help of SLS process (Rapid Prototyping). And found that large thickness electrodes cannot be sintered properly with laser also the density on upper layer is higher as compare to bottom layer. Laser speed can be increase to increase porosity. Qingyu liu et al. researched effect of parameters on the tool electrode wear, he found due to skin effect and area effect the MRR, wear rate, taper rate are different with increase in diameter of the tool. Large diameter result in higher MRR along with higher tool wear rate. The electrode wear rate is more than the work wear rate which leads to increase in tool wear ratio. A tool electrode with higher diameter also results in increase in taper rate. Rimao Zou et al. [5] researched on porous structured steel work-piece and machined it with EDM, and they found that MRR increase with the increase with the pour size. And the minimum MRR is result when the pour size is minimum. Also we can say when the pour size is less than the spark gape it results in minimum MRR. Suresh et al. [6] Researched on the work material $\left(\mathrm{Ti}_{6} \mathrm{Al}_{4} \mathrm{~V}\right)$, with three different electrodes, copper, brass and graphite. And they found that the electrical resistivity and melting point of electrode influence the wear of electrode and MRR of $\mathrm{Ti}_{6} \mathrm{Al}_{4} \mathrm{~V}$ work material. The graphite electrode was more superior to machine this work. It achieved near indented depth, as graphite less resist the electricity and the wear was less as compare to copper and brass.

Srivastava et al. [7] Researched on three electrodes of different material, copper, brass and graphite and they found copper provide superior performance on productivity, also they found that the carbon layer on the work material was very high as compare to other electrode, and they choose the work material aluminum alloy 6061. And they find from the surface finish point of view the graphite electrode was superior. And also by research it is clearly understood that the white layer thickness depends on the electrode material, and is it minimum for brass. Yia et al. [8] researched on die sinking EDM, they replaced the typical tool with the porous electrode of copper, made with the copper balls which are sintered on temperatures for different sample of electrodes. And they found that the MRR improved. Or we can say it as the rough machining ability improved because there the surface finish was poor cause of the non-uniform porous structure of the electrode. Dwevedi and Chaudhary did a research on EDM MRR improvement by rotating the electrode while machining, and they found that the MRR improved by $41 \%$ and also the recast layer thickness reduced and resulted a uniform surface with miner cracks and surface roughness improved by $12 \%$ (Figures 2 and 3 ).

Zeilmann et al. [9] the position of flushing path has an important 
impact on the subsurface hardness because of the facility or difficulty of heating and melts or debris removal. This affects the diffusion of carbon and hydrogen into the workpiece an improper flushing cause the increase in subsurface hardness. Apiwat Muttamara et al. [10] found that carbon has a very important role in forming recast layer in EDM machining, the carbon layer produced in kerosene is rougher and thicker, and then the layer formed in deionized water. In addition the layer formed on gray iron is rougher then the mild steel. And they found that the micro cracks on the layer found were longer in case of water. But in kerosene they were wider. Also the discharge duration effects the crack formation. Longer duration causes longer micro cracks.

Holmberg et al. [11] the results show that grit blasting is a possible method to be used in order to remove RCL after EDM processing. The grit-blasting parameters blasting time and nozzle distance have great influence on the resulting surface integrity generating a RCL-free surface with high compressive residual stresses after exposure times greater than $4 \mathrm{~s}$. Chan et al. [12] Researched and found that if we do sintering on Nano particles of copper, the reduction of porosity in the single film of particles was $37.3 \%$, and the roughness of surface film also decrease by $65.7 \%$. Also the elimination of oxygen content in thin was $91.7 \%$.

Mohammadian et al. [13] Researched on aluminum foam for heat sinks and they found that porous foam insertion improves temperature reduction. And also this practice enhances the temperature uniformity. Yin et al. [14] made a flexible electrical electrode, they made is with the help of facile thermal evaporation, bilayer is made with $\mathrm{CU}$ and $\mathrm{Al}$ was made with this technique whose resistivity has been greatly decreased to $3.05 \mu \Omega \cdot \mathrm{cm}$. The introduction of $\mathrm{Al}$ buffer layer gave a complete growth crystalline of $\mathrm{Cu}$ with decreased residual thermal stress and achieved a very great flexibility.

Koyano et al. [15] made a porous electrode for electro chemical machining, by selective laser sintering. The size of pours can easily be achieved in different size just by varying the speed of selective laser sintering process. If the laser move fast, pours will be of larger size and vice versa. They also found that small pour size and uniformity in size can help in getting good machining. Also decrease in the porous area can be helpful if sufficient flow of electrolyte can be achieved. Xu $\mathrm{H}$, et al. [16] researched on multi hole EDM electrodes with various size of hole diameters. The electrodes they used are made of graphite. They made three electrodes with different arrangement of holes. And the arrangement was E1 $(2,2,2,2) \mathrm{mm}$, E2 $(2,3,2,2) \mathrm{mm}$, E2 $(2,3,2,1.5)$ $\mathrm{mm}$ holes radially. The first hole was in the center rest three are about radially and number of holes of in radially was (1, 6, 12 and 18). They found that E3 electrode has the best MRR and low TWR. The faster the flushing pressure the faster the plasma break and it also helps in increasing the MRR. Also the faster the flushing velocity it is fast to carry away the heat from electrode and it helps in increase in tool life.

Suarez et al. [17] concluded that in this research Borax powder was used as a flux in the sintering process of iron anchor steel 1000R, and they found that borax works as a lubricant too and help in keeping the sintering part separated from the die. And also they found that it can help in maintaining the porosity inside the part. The more the flux used the higher the porosity they get. The percentage of borax they used in mixture was $0.5 \%$ to $6 \%$ and the porosity range they got was from $7.88 \%$ to $13.10 \%$. Research also shows that micro hardness increase with increasing borax percentage and decreasing sintering temperatures. Ohdar et al. [18] researched on EDM of steel 2023 with the help of copper on various parameters and found that for MRR, most important factor is pulse ON and OFF time. On peak current value 12A, pulse ON time 15 micro seconds and pulse off time 3 micro seconds with flushing pressure $0.3 \mathrm{~kg} / \mathrm{cm}^{3}$ it is observed that MRR becomes high. For TWR the important found is peak current followed by pulse ON time. At the value of peak current $14 \mathrm{~A}$, pulse $\mathrm{ON}$ time 5 micro seconds and pulse OFF time 7 micro seconds TWR reduced. Singh et al. [19] used and air assisted multi-hole tool to machine high chromium high carbon die steel, also provided rotation to the tool. The high pressure of argon gas with the rotation of tool helped in keeping the molten drop away from the machining section very fast. Also tool wear decrease due to the passage of air. MRR significantly increased. Flano et al. [20] used copper foil electrode to cut $\mathrm{SiC}$, the foil was having hole cutting inside and they called it chip pocket cause it helps in removing debris white machining. Improved MRR was observed when the jump motion provided to tool. Holes in foil also helped in cooling down the foil temperature. Mohammadian et al. [13] performed a research on EDM for investigating the effect of initial surface roughness of electrode on MRR while EDM process and they found that rougher the initial electrode surface greater the MRR. And these types of initially rough surface electrodes can be used for rough machining. Also tool wear is improved.

\section{Results and Discussion}

Above review of research work leads to author that porous electrode could be a far better choice for roughing and semi finishing as Mohammadian et al. [13] stated that initial surface roughness improves MRR and TW, but it might be problem in solid electrodes which are roughed initially won't be able to maintain same surface roughness after a long use so that gap in research can be filled by permanent porous electrodes because of their complex structure due to porosity and roughness and copper ball sintered electrode can be a better choice there stated by Yia et al. [8]. But due to a large a use it might be possibility that sintering bond of copper get weakens and balls fall down. Also copper balls cost higher than normal copper, also it is a costly procedure to maintain reduction environment during sintering cause if metal get oxidized it won't get sintered. The gap in this is to find a cost effective other solution for making porous electrode. In porous electrode it will be a very good choice to use flushing through inside of the tool so that tool cool down fast air assisted multi hole tool support this idea by Singh et al. [19]. Pour size will also affect the MRR larges the pour size higher the MRR and this idea is supported by $\mathrm{Xu}$ et al. [16]. We can prepare porous electrode with the help of Borax to create diffusion bond between particles without creating reduction environment also borax will help in improving micro hardness of electrode if prepared with this technique this idea supported by Suarez et al. [17]. Also the pour will help in taking debris out of cutting zone without lifting tool and pours will work as chip pocked stated by Flano et al. [20].

\section{Conclusion}

This review contributes the objectives to enhance the material removal rate and to increase the life of electrode by reducing the wear rate of electrode. This paper reviews the past research work done on porous electrodes to improve the life of electrode and to reduce the lift up time of electrode to flush debris and various work on porous electrodes to reduce lift up time.

\section{References}

1. Shibayama T, Kunieda M (2006) Diffusion bonded EDM electrode with micro holes for jetting dielectric liquid. CIRP Ann Manuf Technol 55: 171-174.

2. Guu YH, Hocheng $H$ (2001) Effects of workpiece rotation on machinability 
during electrical-discharge machining. Materials and Manufacturing Processes 16: 91-101.

3. Zhao J, Li Y, Zhang J, Yu C, Zhang Y (2003) Analysis of the wear characteristics of an EDM electrode made by selective laser sintering. J Mater Process Tech 138: 475-478.

4. Amorim FL, Lohrengel A, Neubert V, Higa CF, Czelusniak T (2014) Selective laser sintering of Mo-CuNi composite to be used as EDM electrode. Rapid Prototyp J 20: 59-68.

5. Zou R, Yu Z, Li W, Guo M, Li J (2016) Influence of porous structure on the machining performance of micro EDM. J Mater Process Tech 232: 43-51.

6. Suresh S, Jamil MA, Sulaiman S, Shokor MR, Rozani M (2016) Optimization of electrode material for EDM Die-sinking of Titanium Alloy Grade 5-Ti6AI4V. IJASEIT 6: 534-539.

7. Srivastava A, Kumar A, Datta S, Upadhyay C, Mahapatra SS (2016). Effect of variation of electrode material on machining performance of Al 6061 during EDM operation.

8. Jiang Y, Qi L, Linglei K, Xueliang P, Wansheng Z (2016) Electrical discharge machining for complex cavity with a porous electrode. Procedia CIRP 42: 618-622.

9. Zeilmann RP, Biasin RN, Ost CA, Webber CB Ivaniski TM (2016) The effect of unilateral side flushing on the integrity of the workpiece under different machining conditions. Procedia CIRP 45: 343-346.

10. Muttamara A, Kanchanomai C (2016) Effect of carbon in the dielectric fluid and workpieces on the characteristics of recast layers machined by electrical discharge machining. Metal Mater Trans A 47: 3248-3255.

11. Holmberg J, Wretland A, Berglund J (2016) Grit blasting for removal of recast layer from EDM process on Inconel 718 Shaft: An evaluation of surface integrity. J Mater Eng Perform 25: 5540-5550.
12. Chan HJ, Huang BC, Wang LW, Liao KH, Lo CY (2017) Porosity reduction in inkjet-printed copper film by progressive sintering on nanoparticles. Thin Solid Films 627: 33-38.

13. Mohammadian SK, Zhang Y (2017) Cumulative effects of using pin fin heat sink and porous metal foam on thermal management of lithium-ion batteries. Appl Therm Eng 118: 375-384

14. Yin S, Zhu W, Deng Y, Peng Y, Shen S, et al. (2017) Enhanced electrical conductivity and reliability for flexible copper thin-film electrode by introducing aluminum buffer layer. Mater Des 116: 524-530.

15. Koyano T, Hosokawa A, Igusa R, Ueda T (2017) Electrochemical machining using porous electrodes fabricated by powder bed fusion additive manufacturing process. CIRP Annals-Manufacturing Technology 66: 213-216.

16. Xu H, Gu L, Zhao W, Chen J, Zhang F (2017) Influence of flushing holes on the machining performance of blasting erosion arc machining. Proc Inst Mech Eng B 231: 1949-1960.

17. Suarez HA, Santos AS, Otálora CO (2016) Borax as flux on sintering of iron Ancor Steel 1000® under glow discharge. In Journal of Physics: Conference Series IOP Publishing 687: 012083.

18. Ohdar NK, Jena BK, Sethi SK (2017) Optimization of EDM process parameters using Taguchi Method with Copper Electrode. International Research Journa of Engineering and Technology 4: 2428-2431.

19. Singh NK, Pandey PM, Singh KK (2017) Experimental investigations into the performance of EDM using argon gas-assisted perforated electrodes. Mater Manuf Process 32: 940-951.

20. Flaño O, Zhao Y, Kunieda M, Abe K (2017) Approaches for improvement of EDM cutting performance of $\mathrm{SiC}$ with foil electrode. Precision Engineering 49 $33-40$. 